\title{
Ametropia among school children-A cross-sectional study in a sub-urban municipality in Ghana
}

\author{
Mohammed Abdul-Kabir ${ }^{1 *}$, Daniel Nii Kwashie Bortey ${ }^{1}$, Eghonghon Ehianata Onoikhua ${ }^{2}$, Bright Asare-Bediako ${ }^{1}$ and David Ben Kumah ${ }^{1}$ \\ ${ }^{1}$ Department of Optometry and Visual Science, Kwame Nkrumah University of Science and Technology, Kumasi, Ghana \\ ${ }^{2}$ Department of Optometry, Madonna University, Elele, Rivers State, Nigeria
}

\begin{abstract}
Background: Uncorrected refractive error is a major disease burden among children around the world. Refractive error can lead to childhood blindness. When their vision suffers, children's routine schoolwork and day to day activities also get affected.

Methods: Children whose parents/guardians consented to the study and satisfied the inclusion criteria were taken through a battery of eye examinations. This included visual acuity measurement using a 6-metre Snellen chart, non-cycloplegic retinoscopy, subjective refraction, external ocular examination using a pentorch, anterior and posterior segment examination as well as fundus examination using a direct ophthalmoscope. The association between refractive error and socio-economic status (SES) of parents/guardians was also investigated.

Results: A total of 208 children were studied. There were 101 males (48.6\%) and 107 females (51.4\%). Parents of 52.7\% of the children studied were in the low SES level. The prevalence of refractive error was $30.29 \%$. The commonest refractive error was myopia (22.6\%), followed by astigmatism (5.3\%) and then hyperopia (2.4\%). Only $4(6.3 \%)$ of the pupils with refractive error wore correction. The prevalence of refractive error appeared to increase with age and SES of parents. None of the parents/guardians of the children who wore correction was in the low SES group.

Conclusion: The prevalence of uncorrected refractive error among the pupils was high. We recommend that periodic eye screening in school children should be carried out in such low income settings and public health programs on childhood refractive error should be increased in such settings.
\end{abstract}

\section{Introduction}

Refractive error (ametropia) is an error in focusing of light by the eye from an object onto the retinal plane and is a common cause of visual impairment [1]. It is estimated that about 2.3 billion people worldwide including children have refractive error [2] and is the second leading cause of treatable blindness worldwide [3]. Refractive error consists of myopia, hyperopia and astigmatism [4] and is corrected mainly with spectacles.

Uncorrected refractive error is a major disease burden among children around the world [5]. It results in a number of problems among this high risk group including educational loss, low productivity and impaired quality of life [6-8]. When their vision suffers, children's routine schoolwork and day to day activities also get affected. Children with refractive error are known to have difficulty concentrating on curricular activities [9]. Refractive error can lead to childhood blindness whose consequences are reported to be manifold [10].

Unfortunately, a great majority of children have never had an eye examination [11]. Studies have shown that many basic school pupils with refractive error lack refractive correction, especially in the rural areas [12]. The majority of the people who do not have access to refractive error services live in developing countries and are mainly children [2]. The World Health Organization (WHO) has reported a lack of refraction and spectacle provision in underserved communities, which is believed to have negative effects in such societies in terms of loss of education, loss of future employment opportunities and poor quality of life [13].
Studies have shown that early identification and correction of refractive error optimizes cognitive development and learning ${ }^{14}$. With routine vision screening, refractive error among school children can be detected and corrected. Such periodic programs are necessary in low income settings and developing countries where most of the population do not have access to reasonable quality eye care services [7]. Analysis of the prevalence of undiagnosed ametropia will allow the setting up of preventive programs and initiatives that can provide more accurate interventions aimed at the preservation of visual health ${ }^{15}$. For children, a visual acuity failure threshold of $6 / 12$ (Snellen) has been recommended but $6 / 9$ and $6 / 18$ have also been widely used [11].

As in most African countries, Ghana has no national basic school eye screening program. This study was carried out in the AsokoreMampong Municipality of Ghana to determine the prevalence of uncorrected ametropia among basic school pupils.

\section{Materials and methods}

\section{Study design and sampling}

The research was designed as a prospective cross-sectional,

Correspondence to: Mohammed Abdul-Kabir, Department of Optometry and Visual Science, B9 COS Building, KNUST-Kumasi, Ghana, Tel: +233266307211; Fax: +233266307211; E-mail: kabir265@gmail.com

Key words: refractive error, socio-economic status, childhood refractive error Received: May 13, 2016; Accepted: May 31, 2016; Published: June 04, 2016 
randomized study of all primary school children from 10 to 15 years old in the Asokore-Mampong Municipality of Ghana. This age range was selected because it has been shown to be cost-effective than the lower ages for screening purposes [5] and visual acuities measured in children in this range are more accurate [3]. The municipality was organized into five clusters. Simple random sampling was used to randomly select three out of the five clusters for the study. Within each cluster, two basic schools were randomly selected. Each pupil in a sampled school who satisfied the inclusion criteria was eligible to partake in the study. The total number of students sampled was determined to be 172 using Epi Info version 7.1.4.0, an expected prevalence of $20 \%{ }^{7}$ and a confidence level of $90 \%$.

\section{Screening procedure and data collection}

An informed consent and ocular history were obtained from a parent/guardian of each pupil. Each pupil who returned with a signed consent form was taken through a battery of eye examination. This included visual acuity measurement, with and without prescription if any, using a 6-metre Snellen chart. For visual acuities less than $6 / 9$, the pinhole test was performed from the same distance. Noncycloplegic retinoscopy was performed for all pupils and was followed with subjective refraction. The final prescriptions and the associated best-corrected visual acuities were recorded. External examination was performed with a pentorch, followed by anterior and posterior segment examination as well as fundus examination using a direct ophthalmoscope. All findings obtained were recorded on examination forms designed for this study and diagnoses made accordingly. Subjects who required further examination and management were referred to the University Hospital Eye Clinic for further examination and care. Children with history of ocular surgery, glaucoma and active intraocular disease were excluded from the study.

In addition, the employment status and type of occupation of the parent/guardian of each pupil was obtained. The socio-economic status (SES) of parents was inferred from their respective occupations. Professional occupations such as engineering, accounting, nursing and law were categorized as high SES, occupations within government sectors which are not professional occupations such as civil service and teaching were categorized as medium SES and occupations like trading and farming were categorized as low SES.

For purposes of this study, refractive error was defined as visual acuity of less than 6/9 which improved with pinhole. Refractive error of $-0.50 \mathrm{DS}$ or more was diagnosed as myopia, +1.50DS or more as hyperopia and $0.75 \mathrm{DC}$ or more as astigmatism.

\section{Data analysis}

The Statistical Package for Social Scientists (SPSS) version 16.0 (SPSS, Inc., Chicago, IL, USA) was used to analyze the data. Continuous variables were expressed as mean \pm standard deviation $(\mathrm{M} \pm \mathrm{SD})$. Descriptive statistics and Chi-square test were employed to find significant differences between comparable categorical groups. Statistical significance was set at $\mathrm{p}$ values less than $0.05(\mathrm{p}<0.05)$.

\section{Ethical consideration}

The study was approved by the Department of Optometry and Visual Science, and then reviewed and approved by the Committee on Human Research, Publications and Ethics of the Kwame Nkrumah University of Science and Technology, School of Medical Sciences. A written approval was obtained from headmasters of each of the sampled schools. Informed consent for non-invasive ocular examination was obtained from the parents/guardians of all pupils who took part in the study.

\section{Results \\ Social demographics}

A total of 208 children were studied. There were 101 males (48.6\%) and 107 females (51.4\%). Majority (39.4\%) of the children were 12 years old. Table 1 shows the distribution of age and gender of the study subjects. Parents of $52.7 \%$ of the children studied were in the low socioeconomic status (SES) level. Parents of only $10.6 \%$ pupils were in the high SES level. The distribution of SES with the types of refractive error is shown in table 2 .

The prevalence of refractive error was $30.29 \%$. The commonest refractive error was myopia (22.6\%), followed by astigmatism $(5.3 \%)$ and then hyperopia (2.4\%). Only 4 (6.3\%) of the pupils with refractive error wore correction. This is shown in table 3. Table 4 shows the distribution of previously diagnosed and undiagnosed refractive error. The prevalence of refractive error appeared to increase with age and was statistically significant $(\mathrm{p}=0.031)$. No significant relationship was found between refractive error and gender $(\mathrm{p}=0.124)$.

The association between refractive error among the children and the SES of parents/guardians was examined. The prevalence of refractive error appeared to increase with increasing SES of parents and was statistically significant $(\mathrm{p}=0.041)$. None of the parents/guardians of the children who wore correction was in the low SES level.

\section{Discussion}

This study reported a high prevalence of refractive error among the pupils. Studies on refractive error have reported variable prevalence rates. While studies in South Africa ${ }^{16}$, Nepal, China, Chile, and New Delhi have reported much lower prevalence rates ${ }^{17-21}$, other studies have reported higher rates in other settings [22-24]. These differences are probably due to differences in sample sizes, definitions for refractive error as well as ethnic differences. The commonest refractive error found in this study was myopia, followed by astigmatism and then

Table 1. Distribution of gender with age groups.

\begin{tabular}{|l|l|l|l|}
\hline Gender & Age group in years & \multicolumn{2}{l|}{} \\
\cline { 2 - 4 } & $\mathbf{1 0 - 1 2}$ & $\mathbf{1 3 - 1 5}$ & Total \\
\hline Male & 89 & 12 & 101 \\
\hline Female & 100 & 7 & 107 \\
\hline Total & 189 & 19 & 208 \\
\hline
\end{tabular}

Table 2. Refractive error of pupils and socio-economic status (SES) of parents.

\begin{tabular}{|l|l|l|l|l|}
\hline \multirow{2}{*}{$\begin{array}{l}\text { Refractive } \\
\text { error of pupils }\end{array}$} & \multicolumn{5}{|l|}{ SES of parents (\% of pupils with error) } \\
\cline { 2 - 5 } & Low SES (\%) & $\begin{array}{l}\text { Medium SES } \\
(\%)\end{array}$ & High SES (\%) & Total (\%) \\
\hline Myopia & $7(14.9)$ & $15(31.9)$ & $25(53.2)$ & $47(100)$ \\
\hline Hyperopia & $1(20)$ & $3(60)$ & $1(20)$ & $5(100)$ \\
\hline Astigmatism & $2(18.2)$ & $3(27.3)$ & $6(54.5)$ & $11(100)$ \\
\hline
\end{tabular}

Table 3. Distribution of the types of refractive error among the pupils.

\begin{tabular}{|c|c|c|}
\hline Variables & Frequency & Percentage \\
\hline Myopia & 47 & 74.60 \\
\hline Astigmatism & 11 & 17.46 \\
\hline Hyperopia & 5 & 7.94 \\
\hline Total & 63 & 100 \\
\hline
\end{tabular}


Table 4. Distribution of previously diagnosed and undiagnosed refractive error

\begin{tabular}{|l|c|c|}
\hline Variables & Number & Percentage \\
\hline $\begin{array}{l}\text { Previously Diagnosed } \\
\text { refractive error }\end{array}$ & 6 & 9.52 \\
\hline Undiagnosed refractive error & 57 & 90.48 \\
\hline Total & 63 & 100 \\
\hline
\end{tabular}

hyperopia. Other studies have reported variable trends. Kawuma and Mayeku [21] found the commonest refractive error among children in Kampala District to be astigmatism, followed by hyperopia and then myopia. However, other studies found the commonest refractive error to be myopia, followed by hyperopia and astigmatism [25,26]. These differences in magnitude of the types of refractive error could be due to genetic and environmental differences among study subjects.

The study recorded increasing prevalence of refractive error with age. At age 10 and above, it is expected that emmetropia would be achieved. The increasing prevalence of refractive error could be due to continuous growth or increase in axial length of the eyeball which is not balanced by the power of the refractive media. This phenomenon would lead to increase in myopia, as recorded in this study, thereby increasing the prevalence of refractive error. The high prevalence of myopia could also be due to prolonged close work [27,28]. That no association was found between refractive error and gender could probably be due to the small sample size. Studies have found higher refractive error to be associated with female gender ${ }^{3}$. The high rate of undiagnosed refractive error could be due to the poor access to eye care services in developing countries like Ghana. This puts the educational development of such children in jeopardy. The refractive error could result in unreported poor vision in the classroom as well as an apparent lack of concentration or interest in academic work on the part of the pupils which teachers and parents might not attribute to vision problems.

Prevalence of refractive error also increased with increasing socio-economic status (SES) of parents and the parents of over half of myopic children were in the high SES level. Children of parents with higher SES may undergo more near work as a result of more pressure to study, which could result in the onset of myopia $[29,30]$. The association of refractive error with parent's level of education has been found elsewhere ${ }^{3}$. With advancement in technology, extensive use electronic gadgets and lack of outdoor activities by pupils from medium to high income homes could result in high prevalence of myopia and an increase in the number of avoidable blindness due to refractive error [31-34]. Genetic and ethnic factors may also play a role [35-37]. Majority of parents/guardians were within the low SES level. The low level of income of such parents/guardians could be a barrier to accessing eye care for their children. It has been described elsewhere that access to eye care services, public awareness of the need for them, and availability of spectacles have not yet reached adequate levels in developing countries [5]. It is through screening programs that the visual problems of children with such needs are detected and their parents/guardians duly notified to seek eye care for their wards.

\section{Conclusion}

The prevalence of uncorrected refractive error among the pupils was high. We recommend that periodic eye screening in school children should be carried out in such low income settings and public health programs on childhood refractive error should be increased in such settings. Children constitute a particularly vulnerable group within whom uncorrected refractive error may have a dramatic impact on learning capabilities and educational potential. Increasing public health efforts with respect to education of parents on refractive errors in developing countries and low income settings could go a long way to help in the fight against childhood blindness caused by refractive error.

\section{References}

1. Jalis M, Ashfaq MW, Imdad A (2015) Use of Bruckner Test for the detection of significant refractive errors in children. JRMC 19: 200-203.

2. Holden BA, Sulaiman S, Knox K (2000) The challenge of providing spectacles in the developing world. CEHJ 13: 9-10.

3. Dandona R, Dandona L (2001) Refractive error blindness. Bull World Health Organ 79: 237-243. [Crossref]

4. Williams KM, Verhoeven VJ, Cumberland P, Bertelsen G, Wolfram C, et al. (2015) Prevalence of refractive error in Europe: the European Eye Epidemiology (E(3)) Consortium. Eur J Epidemiol 30: 305-315. [Crossref]

5. Baltussen R, Naus J, Limburg H (2009) Cost-effectiveness of screening and correcting refractive errors in school children in Africa, Asia, America and Europe. Health Policy 89: 201-215. [Crossref]

6. Hashemi H, Rezvan F, Beiranvand A, Papi OA, Hoseini Yazdi H, et al. (2014) Prevalence of Refractive Errors among High School Students in Western Iran. $J$ Ophthalmic Vis Res 9: 232-239. [Crossref]

7. Prabha V, Meriton SA (2016) A cross sectional study on refractive error among schoo children aged 6 to 17 years in Chennai, India. Int J Community Med Public Health 3: $71-73$.

8. Hugh R Taylor, MD Fraco (2000) Refractive errors: magnitude of the need. Community Eye Health 13: 1-2. [Crossref]

9. Dulani N, Dulani H (2014) Prevalence of refractive errors among school children in Jaipur, Rajasthan. Int J Sci Stud 2: 52-55.

10. Shrestha RK, Joshi MR, Ghising R, Pradhan P, Shakya S, et al. (2006) Ocular morbidity among children studying in private schools of Kathmandu valley: A prospective cross sectional study. Nepal Med Coll J 8: 43-46.

11. Wedner SH, Ross DA, Balira R, Kaji L, Foster A (2000) Prevalence of eye diseases in primary school children in a rural area of Tanzania. Br J Ophthalmol 84: 1291-1297. [Crossref]

12. Powell C, Wedner S, Richardson S (2005) Screening for correctable visual acuity deficits in school-age children and adolescents. Cochrane Database Syst Rev: CD005023. [Crossref]

13. World Health Organization. Elimination of avoidable visual disability due to refractive errors. WHO/PBL/00.79. Geneva, 2000. http://whqlibdoc.who.int/hq/2000/WHO PBL 00.79.pdf

14. Roch-Levecq AC, Brody BL, Thomas RG, Brown SI (2008) Ametropia, preschoolers' cognitive abilities, and effects of spectacle correction. Arch Ophthalmol 126: 252-258.

15. Gull A, Raza A (2014) Visual screening and refractive errors among school aged children. JRMC 18: 97-100.

16. Naidoo KS, Raghunandan A, Mashige KP, Govender P, Holden BA, et al. (2003) Refractive error and visual impairment in African children in South Africa. Invest Ophthalmol Vis Sci 44: 3764-3770. [Crossref]

17. Zhao J, Pan X, Sui R, Munoz SR, Sperduto RD, et al. (2000) Refractive Error Study in Children: results from Shunyi District, China. Am J Ophthalmol 129: 427-435. [Crossref]

18. Pokharel GP, Negrel AD, Munoz SR, Ellwein LB (2000) Refractive Error Study in Children: results from Mechi Zone, Nepal. Am J Ophthalmol 129: 436-444. [Crossref]

19. Maul E, Barroso S, Munoz SR, Sperduto RD, Ellwein LB (2000) Refractive Error Study in Children: results from La Florida, Chile. Am J Ophthalmol 129: 445-454. [Crossref]

20. Murthy GV, Gupta SK, Ellwein LB, Muñoz SR, Pokharel GP, et al. (2002) Refractive error in children in an urban population in New Delhi. Invest Ophthalmol Vis Sci 43: 623-631. [Crossref]

21. Kawuma M, Mayeku R (2002) A survey of the prevalence of refractive errors among children in lower primary schools in Kampala district. Afr Health Sci 2: 69-72. [Crossref]

22. Lin LL, Shih YF, Tsai CB, Chen CJ, Lee LA, et al. (1999) Epidemiologic study of 
ocular refraction among schoolchildren in Taiwan in 1995. Optom Vis Sci 76: 275-281. [Crossref]

23. Fan DS, Lam DS, Lam RF, Lau JT, Chong KS, et al. (2004) Prevalence, incidence, and progression of myopia of school children in Hong Kong. Invest Ophthalmol Vis Sci 45 : 1071-1075. [Crossref]

24. Saw SM, Chua WH, Hong CY, Wu HM, Chan WY, et al. (2002) Nearwork in earlyonset myopia. Invest Ophthalmol Vis Sci 43: 332-339. [Crossref]

25. Ayub A, Imran A, Saima A (2007) Prevalence of undetected refractive errors among school children. Biomedica 23: 96-101.

26. Pavithra MB, Maheshwaran R, Rani SMA (2013) A study on the prevalence of refractive errors among school children of 7-15 years age group in the field practice areas of a medical college in Bangalore. Int J Med Sci Public Health 2: 641-645.

27. Mutti DO, Jones LA, Moeschberger ML, Zadnik K (2000) AC/A ratio, age, and refractive error in children. Invest Ophthalmol Vis Sci 41: 2469-2478. [Crossref]

28. Ip JM, Huynh SC, Robaei D, Kifley A, Rose KA, et al. (2008) Ethnic differences in refraction and ocular biometry in a population-based sample of 11-15-year-old Australian children. Eye (Lond) 22: 649-656. [Crossref]

29. Angle J, Wissmann DA (1980) The epidemiology of myopia. Am J Epidemiol 111: 220-228. [Crossref]
30. Hung GK, Ciuffreda KJ (2001) The effect of nearwork on transient and permanent myopia [ARVO Abstract]. Invest Ophthalmol Vis Sci 42: S392.

31. Kim SH, Suh YW, Choi YM, Han JY, Nam GT, et al. (2015) Effect of watching 3-dimensional television on refractive error in children. Korean J Ophthalmol 29: 5357. [Crossref]

32. Attebo K, Ivers RQ, Mitchell P (1999) Refractive errors in an older population: the Blue Mountains Eye Study. Ophthalmology 106: 1066-1072. [Crossref]

33. Wensor M, McCarty CA, Taylor HR (1999) Prevalence and risk factors of myopia in Victoria, Australia. Arch Ophthalmol 117: 658-663. [Crossref]

34. Goh WS, Lam CS (1994) Changes in refractive trends and optical components of Hong Kong Chinese aged 19- 39 years. Ophthalmic and Physiological Optics 14: 378-82.

35. Mutti DO, Mitchell GL, Moeschberger ML, Jones LA, Zadnik K (2002) Parental myopia, near work, school achievement, and children's refractive error. Invest Ophthalmol Vis Sci 43: 3633-3640. [Crossref]

36. Saw SM, Chua WH, Hong CY, Wu HM, Chan WY, et al. (2002) Nearwork in earlyonset myopia. Invest Ophthalmol Vis Sci 43: 332-339. [Crossref]

37. Kleinstein RN, Jones LA, Hullett S, Kwon S, Lee RJ, et al. (2003) Refractive error and ethnicity in children. Arch Ophthalmol 121: 1141-1147. [Crossref]

Copyright: (C2016 Abdul-Kabir M. This is an open-access article distributed under the terms of the Creative Commons Attribution License, which permits unrestricted use, distribution, and reproduction in any medium, provided the original author and source are credited. 